\title{
THE INFLUENCE OF 2,3-DIHYDROXYBENZALDEHYDE THIOSEMICARBAZONE ON CATALYTIC CURRENTS IN THE SYSTEM MOLYBDENUM(VI) - POTASSIUM CHLORATE IN ACID SULFATE SOLUTIONS
}

\author{
Ludmila Chiriac ${ }^{\mathrm{a}}$, Tatiana Cazac ${ }^{\mathrm{a}}$, I. Povar ${ }^{\mathrm{a} *}$ and M. Revenco ${ }^{\mathrm{b}}$ \\ ${ }^{a}$ Institute of Chemistry, Academy of Sciences of Moldova,3 Academiei str., Chisinau MD-2028, Republic of Moldova \\ ${ }^{b}$ State University of Moldova, 60 A. Mateevici str., Chisinau MD-2009, Republic of Moldova \\ *E-mail: ipovar@yahoo.ca, Phone:+(373) 22739736
}

\begin{abstract}
The polarographic catalytic current in acid solutions of $\mathrm{Mo}(\mathrm{VI})$, 2,3-dihydroxybenzaldehyde thiosemicarbazone (TSC 2,3-DHBA) and chlorate ions has been investigated. The scheme of reactions, taking place in the solutions and on the electrode, has been proposed. The increase of the catalytic current is explained by the formation of an active intermediate complex $\left[\mathrm{Mo}(\mathrm{V}) \cdot \mathrm{TSC} 2,3-\mathrm{DHBA}\left(\mathrm{ClO}_{3}^{-}\right)\right]$. The rate constant of this complex formation $\mathrm{K}=2.56 \cdot 10^{6} \mathrm{~mol}^{-1} \cdot \mathrm{dm}^{3} \cdot \mathrm{s}^{-1}$, the activation energy $\mathrm{E}_{\mathrm{a}}=15.9 \mathrm{kcal} \cdot \mathrm{mol}^{-1}$ and the reaction activation entropy $\Delta \mathrm{S}_{\mathrm{a}}^{\neq}=-23.5$ e.u. have been calculated.
\end{abstract}

Keywords: voltammetry, catalytic current, molybdenum, thiosemicarbazone 2,3-dihydroxybenzaldehyde, chlorate of potassium.

\section{Introduction}

The influence of aromatic hydroxyl-containing compounds on the kinetics and mechanism of reactions in solutions involving molybdenum(VI), chlorate- [1-8] and bromate-ions [9] is rather different. So, in a solution with a small content of phenol and large enough concentrations of $\mathrm{Mo}(\mathrm{VI})$ and $\mathrm{KClO}_{3}$ the maximum catalytic wave arises in the area of the potentials matching the second form of Mo(III) on electrode [2].

Catehol [1], 2,3-dihydroxybenzaldehyde (2,3-DHBA) [4] as well as mandelic acid (HMand) [3,5,6] stabilize certain forms of $\mathrm{Mo}(\mathrm{V})$ and $\mathrm{Mo}(\mathrm{III})$, formed during the polarographic stepwise reduction of $\mathrm{Mo}(\mathrm{VI})$ in solutions containing $\mathrm{Na}_{2} \mathrm{SO}_{4}$ as supporting electrolyte $(\mathrm{pH} 1-2.5)$. Two reduction waves for $\mathrm{Mo}(\mathrm{VI})$ complexes into $\mathrm{Mo}(\mathrm{V})$ and $\mathrm{Mo}(\mathrm{III})$ complexes were registered on polarograms. The presence of $\mathrm{ClO}_{3}{ }_{3}^{-}$ions proves a large increase of the catalytic current on the potentials of the first wave of reduction for Mo (VI). This effect allows an increasing of the sensitivity of the $\mathrm{Mo}(\mathrm{VI})$ determination.

The catalytic adsorptive voltammetry with accumulation [5-9] allows an additional increasing of the sensitivity for the molybdenum determination.

The present work is dedicated to the investigation of the nature of polarographic current in solutions containing $\mathrm{Mo}(\mathrm{VI})$, chlorate-ions and 2,3-dihydroxybenzaldehyde thiosemicarbazone (TSC 2,3-DHBA). The special attention is given to the influence of TSC 2,3-DHBA on the catalytic current in the system Mo (VI) - $\mathrm{KClO}_{3}$, as well as to the comparison of these results with those obtained in the presence of Catehol [1], 2,3-DHBA [4] and HMand [3, 5-9].

\section{Experimental part}

The measurements of polarographic catalytic currents were carried out using the polarograph PU-1 (Russia) in the thermostated $\left(25 \pm 0.1^{\circ} \mathrm{C}\right)$ three-electrode cell containing: the $\operatorname{MDE}\left(2.45 \mathrm{mg}^{2 / 3} \mathrm{c}^{-1 / 2}\right)$ working drop electrode (a), the saturated calomel electrode (SCE) as a reference electrode (b) and a platinum wire as an auxiliary electrode (c).

The $\mathrm{pH}$ values were determined with an universal $\mathrm{pH}$-meter with a glass electrode.

The initial molybdenum(VI) solution was prepared from the chemically pure $\mathrm{Na}_{2} \mathrm{MoO}_{4} \cdot 2 \mathrm{H}_{2} \mathrm{O}$ salt. The purity of other reagents was of the analytical or chemically pure grades. The ligand standard solution (TSC 2,3-DHBA) with the concentration of $5 \cdot 10^{-5} \mathrm{~mol} / \mathrm{dm}^{3}$ was prepared as follows: an exact weighted amount of the reagent was placed in a 200 $\mathrm{cm}^{3}$ volumetric flask, then bidistilled water was added, the mixture was carefully mixed until the reagent full dissolution, filled up to the mark and mixed again. The aqueous solution of TSC 2,3-DHBA is unstable to light, thus every two day we prepared fresh solutions of this ligand.

Before the registration of the polarogram, the investigated solutions were deoxygenated by blowing off a current of the electrolytic hydrogen within 20 minutes. 


\section{Results and Discussion}

In the $\mathrm{Mo}(\mathrm{VI})$ acid solutions at $\mathrm{pH} 1.0-2.5$ in the presence of chlorate-ions on polarograms there are two catalytic waves. They correspond to the potentials of the first and the second reduction waves of Mo(VI) and testify the catalytic activity for both $\mathrm{Mo}(\mathrm{V})$ and Mo(III) species. In the presence of TSC 2,3-DHBA, the catalytic wave in the form of a big maximum, as well as for 2,3-DHBA [4], covers the area of potentials for the first and second waves. However under the conditions of the greatest display of catalytic effects and small concentrations of Mo(VI) (less than $5 \cdot 10^{-6} \mathrm{~mol} /$ $\mathrm{dm}^{3}$ ), the potential of maximum corresponds to the first catalytic wave in the system $\mathrm{Mo}(\mathrm{VI})-\mathrm{ClO}_{3}^{-}$, i.e. its occurrence is associated with the formation of an active form of $\mathrm{Mo}(\mathrm{V})$.

The occurrence of a maximum and the current falling at potentials more negative than $\mathrm{E}_{\max }$ are associated with a decreasing of the concentration of $\mathrm{Mo}(\mathrm{V})$ active form in the near-electrode layer and transformation of $\mathrm{Mo}(\mathrm{V})$ into Mo (III). Moreover, in solutions containing $\mathrm{Mo}(\mathrm{VI})$, an oxidant $\left(\mathrm{KClO}_{3}\right)$ and an organic surface-active ligand (TSC 2,3DHBA), the occurrence of a wave in the form of a big maximum may be associated with the adsorption of the ligand and /or its complexes with Mo(VI), on the mercury surface. In such a case the concentration in the near-electrode layer is more important, the speed of the chemical reaction is increasing. This processus is determining the speed of the catalytic process entirely. It is necessary to note down that the catalyst complex particles are in the monomeric forme, when the molybdenum (VI) concentration in investigated solutions has been below $1 \cdot 10^{-4} \mathrm{~mol} / \mathrm{dm}^{3}$. In order to explain the nature of the maximum, we have investigated the influence of $\mathrm{pH}$, temperature, height of the mercury column above the capillary as well as the concentrations of TSC 2,3-DHBA, $\mathrm{Mo}(\mathrm{VI})$ and $\mathrm{ClO}_{3}{ }^{-}$ions on the magnitude of the maximal current $I_{p}$.

The catalytic nature of the current in the system $\mathrm{Mo}(\mathrm{VI})$ - TSC 2,3-DHBA - $\mathrm{ClO}_{3}^{-}$is proved by a high value of the temperature factor equal to $7 \%$ per degree.

The independence of the current magnitude in solutions of $\mathrm{Mo}(\mathrm{VI})$ complexes with TSC 2,3-DHBA and $\mathrm{ClO}_{3}$ on the height of the mercury column above the capillary confirms the volumetric-kinetic nature of the rate for the ratedetermining reaction of the catalytic process.

The dependence of the Ip value from concentration of the oxidant ( $\mathrm{KClO} 3)$, having the form of a curve with an inflection point and a saturation region (Fig. 1, curve 1) testifies about the formation of intermediate active complex (IAC).

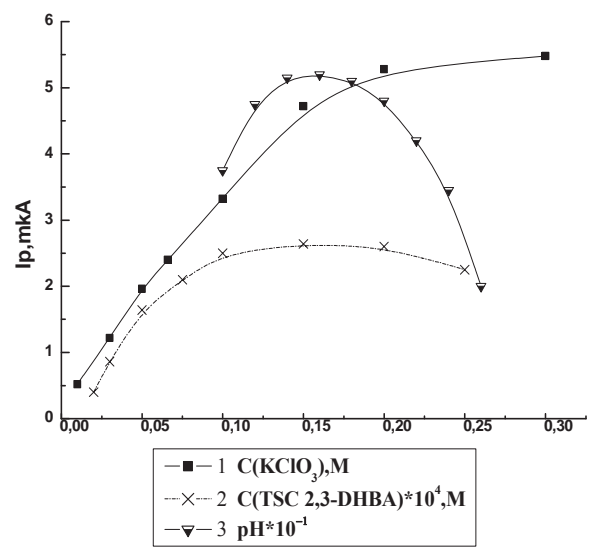

Fig.1. Dependence of $\mathrm{I}_{\mathrm{p}}$ on the concentration of $\mathrm{KClO}_{3}$, TSC 2,3-DHBA and pH: $0.2 \mathrm{M} \mathrm{Na}_{2} \mathrm{SO}_{4}+\mathrm{O.05}_{2} \mathrm{M} \mathrm{H}_{2} \mathrm{SO}_{4}(\mathrm{pH}$ 1.4-1.6). The concentrations: $1 \cdot 10^{-6} \mathrm{M}$ Mo(VI) (curves 1,2 and 3), $1.5 \cdot 10^{-5} \mathrm{M}$ TSC 2,3-DHBA $(1,3), 0.1 \mathrm{M} \mathrm{KCIO}_{3}$ (2) and $0.2 \mathrm{M} \mathrm{KClO}_{3}(3)$. curve 2).

The curve of Ip dependence on the ligand concentration (TSC 2,3-DHBA) passes through a maximum (fig. 1, Initially the activating action of the ligand is increasing with the growth of concentration, reaches a peak and then decreases. The presence of the ligand in the coordination area of the catalyst gives rise to acceleration of the IAC formation. When in the coordination sphere of catalyst there are seats accepting the oxidant species $\mathrm{KClO}_{3}$, the catalytic process is in progress. If, under certain conditions the ligand blocks completely the coordination seats around the catalyst, its activity decreases. The maximal value of the current has been observed at the ligand concentration equal to $1.5 \cdot 10^{-5}$ $\mathrm{mol} / \mathrm{dm}^{3}$.

The optimal $\mathrm{pH}$ range is $1.5-1.6$. The influence of the $\mathrm{pH}$ value (fig. 1, curve 3 ) may be connected with generation of a suitable for coordination form of the molybdenum and/or of the ligand, controlled by photolytic equilibra. Moreover, the ions of hydrogen participate in the redox reaction leading to the regeneration of depolarizer. 
The dependence of the catalytic current magnitude on various concentration factors in solutions of Mo(VI) complexes containing 3-DHBA or TSC-2,3-DHBA has the similar character, and is explained by a common mechanism of the catalytic process in these systems. The general scheme of the catalytic process in such systems can be presented by following chemical and electrochemical reactions (for simplicity charges of particles are omitted):

1) Formation in solution of a complex of molybdenum (VI) with the organic ligand L

$\mathrm{Mo}(\mathrm{VI})+\mathrm{L} \leftrightarrow[\mathrm{Mo}(\mathrm{VI}) \mathrm{L}]$

2) Reduction of the formed complex on electrode

$[\mathrm{Mo}(\mathrm{VI}) \mathrm{L}]+\mathrm{e}^{-} \rightarrow[\mathrm{Mo}(\mathrm{V}) \mathrm{L}]$

$3)$ Formation of an intermediate active complex with the oxidant species $\left(\mathrm{ClO}_{3}{ }^{-}\right)$and its adsorption on the electrode surface

$[\mathrm{Mo}(\mathrm{V}) \mathrm{L}]+\mathrm{ClO}_{3}^{-} \leftrightarrow\left[\mathrm{Mo}(\mathrm{V}) \mathrm{L}\left(\mathrm{ClO}_{3}^{-}\right)\right] \leftrightarrow\left[\mathrm{Mo}(\mathrm{V}) \mathrm{L}\left(\mathrm{ClO}_{3}^{-}\right)\right]_{\mathrm{ads}}$

4) Redox-regeneration of the catalyst.

The IAC, formed according to the reaction (3), undergoes further changes leading to its disintegration in addition to the catalyst regeneration. As it has been shown by the authors [10] by studying the system $\mathrm{Mo}(\mathrm{VI})-\mathrm{H}_{2} \mathrm{C}_{2} \mathrm{O}_{4}-\mathrm{ClO}_{3}^{-}$, the redox regeneration of the catalyst can occur by two ways:

a) In the polarographically-active complex (PAC) $\left[\mathrm{Mo}(\mathrm{V}) \mathrm{L}\left(\mathrm{ClO}_{3}^{-}\right)\right]$an electronic charge transfer from molybdenum on the oxidant $\left(\mathrm{ClO}_{3}^{-}\right)$with a subsequent intracomplex oxidation and regeneration of the catalyst in its higher degree of oxidation, takes place

$\left[\mathrm{Mo}(\mathrm{V}) \mathrm{L}\left(\mathrm{ClO}_{3}^{-}\right)\right]+2 \mathrm{H}^{+} \rightarrow[\mathrm{Mo}(\mathrm{VI}) \mathrm{L}]+\mathrm{ClO}_{2}+\mathrm{H}_{2} \mathrm{O}$

b) An electronic density shift in the PAC from the oxidant to molybdenum occurs and as a result the catalyst is regenerated in the lowest oxidation degree

$\left[\mathrm{Mo}(\mathrm{V}) \mathrm{L}\left(\mathrm{ClO}_{3}^{-}\right)\right]+2 \mathrm{H}^{+}+\mathrm{e}^{-} \rightarrow[\mathrm{Mo}(\mathrm{V}) \mathrm{L}]+\mathrm{ClO}_{2}+\mathrm{H}_{2} \mathrm{O}$.

The authors of [10] have shown that on the polarograms of molybdenum(VI) and $\mathrm{H}_{2} \mathrm{C}_{2} \mathrm{O}_{4}$ in the presence of $\mathrm{ClO}_{3}^{-}$ions, two waves can be observed, second wave being higher the first one. For small Mo(VI) concentrations and $\mathrm{H}_{2} \mathrm{C}_{2} \mathrm{O}_{4}$ concentrations $\left(\approx 2.5 \cdot 10^{-3} \mathrm{~mol} / \mathrm{dm}^{3}\right)$ only one peak on the polarograms, matching the catalytic current of reduction of complexes Mo (V) in Mo (III) is registered. For this reason authors considered that the catalyst regeneration occurs in its lowest degree of oxidation according equation (5). In our researches we have found, that for small ligand (concentrations $\left(<3 \cdot 10-\mathrm{mol} / \mathrm{dm}^{3}\right)$, one high sharp maximum corresponding to the first wave of reduction of the complex $\mathrm{Mo}(\mathrm{VI})$ to $\mathrm{Mo}(\mathrm{V})$ has been registered, and therefore it is more probable that the catalyst regeneration proceeds according to the first mechanism, i.e. the catalyst is regenerated in the highest oxidation state.

The investigation of $\mathrm{Mo}(\mathrm{VI})-\mathrm{Catehol}-\mathrm{ClO}_{3}{ }^{-}[1,2]$ and $\mathrm{Mo}(\mathrm{VI})-2,3-\mathrm{DHBA}-\mathrm{ClO}_{3}{ }^{-}$systems [4] show that for small concentrations of ligand $\left(<5 \cdot 10^{-5} \mathrm{~mol} / \mathrm{dm}^{3}\right)$ one sharp peak is observed on polarograms (see fig. 1, curve 3 [1]). With an increasing of the catehol or 2,3-DHBA concentrations, this peak becomes larger, without a clearly expressed top and the current decreases to more negative potentials. By a further increase of the ligand concentration $\left(>5 \cdot 10^{-5} \mathrm{~mol} / \mathrm{dm}^{3}\right)$ [4], the peak bifurcates and for concentrations more than $1 \cdot 10^{-4} \mathrm{~mol} / \mathrm{dm}^{3}$ the second maximum becomes slightly higher than the first one. It is quite likely, that this phenomenon is associated not only with an adsorption of complexes on the electrode surface as it was supposed in [6], but also with a regeneration of the catalyst in its lowest degree of oxidation. For TSC 2,3-DHBA the study of influence of higher concentrations on $\mathrm{I}_{\mathrm{p}}$ is impossible because of its poor solubility.

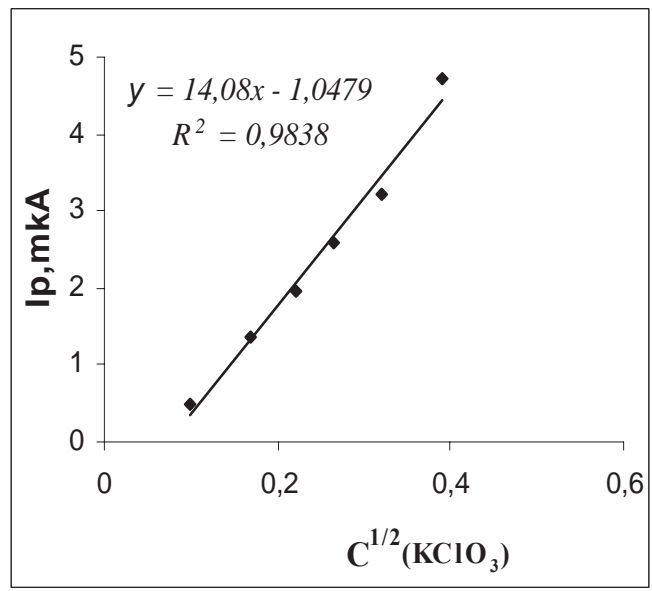

Fig.2. Dependence of $\mathrm{I}_{\mathrm{p}}$ on $\mathrm{C}^{1 / 2}\left(\mathrm{KClO}_{3}\right)$ with $1 \cdot 10^{-6} \mathrm{M} \mathrm{Mo}(\mathrm{VI}), 1.5 \cdot 10^{-5} \mathrm{M}$ TSC 2,3-DHBA, pH 1.45 . 
The reaction (3) is the rate limiting and consequently defines the rate of electrode process. The rate constant of PAC formation has been calculated according to Koutetski's equation $i_{k} / i_{d}=0,81 \sqrt{n K C_{s} t}$ in solutions with the TSC 2,3DHBA concentration of $1.5 \cdot 10^{-5} \mathrm{~mol} / \mathrm{dm}^{3}$ in the area of $\mathrm{I}_{\mathrm{p}}$ linear dependence on $\mathrm{C}^{1 / 2}\left(\mathrm{KClO}_{3}\right)$ (fig.2), i.e. in conditions of a pseudo-ion-molecular reaction (where $i_{k}$ is the catalytic current equal to $I_{p}-I_{d} ; I_{d}-$ diffusion current of reduction of the complex Mo (VI) into Mo (V), recalculated for the Mo (VI) concentration of $1 \cdot 10^{-6} \mathrm{~mol} / \mathrm{dm}^{3}, \mathrm{n}$ - the number of electrons equal to 1; $\mathrm{Cs}$ - concentration of oxidant $\mathrm{KClO}_{3}$ and $\tau$ is the dropping period of capillary, $3.6 \mathrm{~s}$ ).

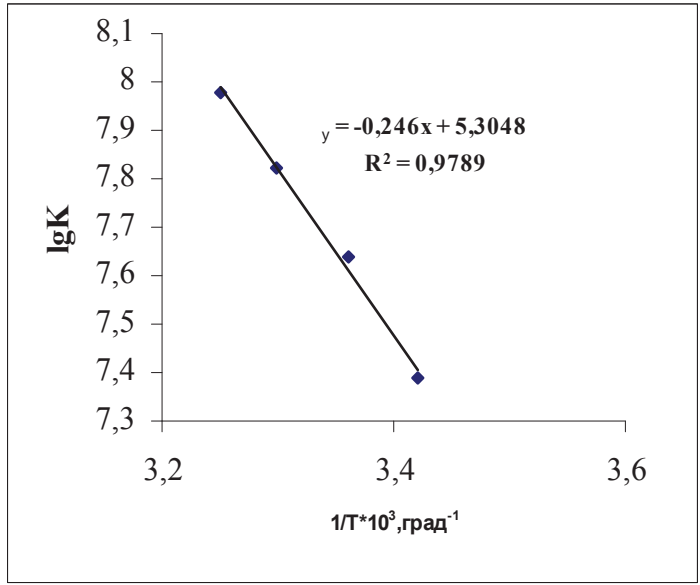

Fig.3. Dependence of $\log \mathrm{K}$ on $1 / \mathrm{T}$ for $1 \cdot 10^{-6} \mathrm{M}$ Mo (VI), $1.5 \cdot 10^{-5} \mathrm{M}$ TSC 2,3-DHBA, pH 1.5 .

From the function $\log \mathrm{K}=\mathrm{f}(1 / \mathrm{T})$ (fig. 3 ) within the temperature range of $20-35^{\circ} \mathrm{C}$ the activation energy and entropy have been calculated according to [11]. The values of the PAC formation rate constant, as well as its activation energy and entropy are presented in Table 1.

Table 1

Kinetic and thermodynamic characteristics of catalytic processes in solutions of Mo (VI) with catehol, 2,3-DHBA, TSC 2,3-DHBA or HMand complexes and chlorate-ions

\begin{tabular}{|c|c|c|c|c|}
\hline Ligand - activator & $\begin{array}{c}\mathrm{K} \cdot 10^{6}, \\
\mathrm{~mol}^{-1} \cdot \mathrm{dm}^{3} \cdot \mathrm{c}^{-1}\end{array}$ & $\begin{array}{c}\mathrm{E}_{\mathrm{a}}, \\
\mathrm{kcal} \cdot \mathrm{mol}^{-1}\end{array}$ & $\begin{array}{c}\Delta \mathbf{S}_{\mathrm{a}}^{ \pm}, \\
\text {e. } \mathrm{u} .\end{array}$ & References \\
\hline Catehol & 8.2 & 16,6 & $-26,0$ & 1 \\
\hline 2,3-DHBA & 2.5 & 14,0 & $-28,3$ & 4 \\
\hline TSC 2,3-DHBA & 2.56 & 15.9 & -23.5 & - \\
\hline HMand & 220 & 14,3 & $-20,4$ & 3 \\
\hline
\end{tabular}

The found values of the rate constant for PAC formation $\left[\mathrm{Mo}(\mathrm{V})\right.$ TSC 2,3-DHBA $\left(\mathrm{ClO}_{3}^{-}\right)$], its activation energy and entropy testify about a high catalytic activity of systems. According to the activation influence, TSC 2,3-DHBA is close to catehol and 2,3-DHBA. The large negative values of entropy recognize the spatial difficulties arising at the introduction of $\mathrm{ClO}_{3}{ }^{-}$ions in the coordination sphere of $\mathrm{Mo}(\mathrm{V})$ complexes. As it can be seen from the values of activation entropy (Table 1), the involvement of $\mathrm{ClO}_{3}^{-}$ions in the coordination sphere of $\mathrm{Mo}(\mathrm{V})$ complexes with HMand and TSC 2,3-DHBA occurs easier; therefore the activation action of this ligand is higher. On the polarograms of Mo(VI) complexes with TSC 2,3-DHBA and HMand in the presence of $\mathrm{KClO}_{3}$, the peaks have the highest $\mathrm{I}_{\mathrm{p}}$ values. The minimum concentration of $\mathrm{Mo}(\mathrm{VI})$ ensuring the appearance of the peak on the polarogram is $4 \cdot 10^{-8} \mathrm{~mol} / \mathrm{dm}^{3}$ in the case of HMand while for TSC 2,3-DHBA this value is $2.5 \cdot 10^{-8} \mathrm{~mol} / \mathrm{dm}^{3}$

The catalytic reaction in the system $\mathrm{Mo}(\mathrm{VI})$ - TSC 2,3-DHBA - $\mathrm{ClO}_{3}^{-}$is very selective and can serve for the metal - catalyst determination of the molybdenum. The optimal conditions for this determination are following: $1.5 \cdot 10^{-5}$ $\mathrm{mol} / \mathrm{dm}^{3} \mathrm{TSC} 2,3-\mathrm{DHBA}, 0.2 \mathrm{M} \mathrm{KClO}_{3}, 0.2 \mathrm{M} \mathrm{Na}_{2} \mathrm{SO}_{4}, 0.05 \mathrm{M} \mathrm{H}_{2} \mathrm{SO}_{4}(\mathrm{pH} 1.4-1.6)$. The linearity of the function $\mathrm{I}_{\mathrm{p}}$ $=\mathrm{f}\left(\mathrm{C}_{\mathrm{Mo}}\right)$ was observed in the concentration range $(0.25-10) \cdot 10^{-7} \mathrm{~mol} / \mathrm{dm}^{3}$. For the Mo(VI) determination the presence of $\mathrm{Tl}$ (I), Cu (II), Pb (II), Mn (II), Zn (II), Co (II), Ni (II), Bi (III), Cr (III), Sn (IV), Te (IV), Se (IV) in the ratio 1:10; As (III), $\mathrm{Sb}$ (III), Fe (III), W (VI) in the ratio 1:1 do not interfere. The presence of large amounts of As (III), Sb (III), Fe (III) 
and any amounts of $\mathrm{V}(\mathrm{V})$ and $\mathrm{Cr}(\mathrm{VI})$ leads to an increase of the Mo(VI) catalytic wave. The study of this influence is a purpose of our further research. At the ratio Mo(VI): $\mathrm{W}(\mathrm{VI})>1: 1, \mathrm{I}$ of molybdenum decreases, that is related, possibly, with an involvement of ligand in the complex formation with $\mathrm{W}(\mathrm{VI})$ and the formation of catalytic waves of tungsten.

Mandelic acid has been proposed for analytical purposes and is used owing to its good solubility and greater stability. Using the catalytic current of chlorate-ions, Mo (VI) in the presence of HMand has been determined in lizimetric solutions and plants (tobacco leaves, hay beans ashes) [3]. The use of catalytic voltammetry with an adsorptive accumulation has allowed to authors [5-9] developing sensitive methods of the Mo (VI) determination in natural waters [5], while using tairon as a ligand - in river, well and artesian waters, in cucumbers, tomatoes and carrots [8]. The perspective to use the system $\mathrm{Mo}(\mathrm{VI}))$ - TSC 2,3-DHBA - $\mathrm{ClO}_{3}{ }^{-}$for determination of molybdenum is attractive by its selectivity.

\section{Conclusions}

The polarographic catalytic currents in acid solutions, containing $\mathrm{Mo}(\mathrm{VI})$, chlorate-ions and 2,3-dihydroxybenzaldehyde thiosemicarbazone (TSC 2,3-DHBA) have been investigated, the schemes of the reactions proceeding in solution and on electrode were proposed. The increase of the catalytic current in the presence of ligand is explained by the formation in solution of an intermediate active complex [Mo(V) TSC 2,3-DHBA $\left.\left(\mathrm{ClO}_{3}^{-}\right)\right]$. The rate constant of this complex formation $\mathrm{K}=2.56 \cdot 10^{6} \mathrm{~mol}^{-1} \cdot \mathrm{dm}^{3} \cdot \mathrm{s}^{-1}$, the activation energy $\mathrm{E}_{\mathrm{a}}=15.9 \mathrm{kcal} \cdot \mathrm{mol}^{-1}$ and the reaction activation entropy $\Delta \mathrm{S}_{\mathrm{a}}^{\neq}=-23.5$ e.u. have been calculated.

These values testify about the high catalytic activity of the studied system. The possibility of the molybdenum determination by means of the catalytic current has been shown.

\section{Acknowledgments}

This work was done with the support of the SCOPES 2009-2012 joint research grant

\section{References}

[1]. Chikryzova, E.G.; Chiriac, L. The determination of pyrocatechol and oxy-acids using the polarographic catalytic current in solutions of molybdenum (VI) and chlorate-ions / J. Anal. Chem.- 1974 - V. 29, No 12 - p. 2420 2426.

[2]. Chiriac, L.; Chikryzova, E.G. The influence of some aromatic hydroxyl-containing compounds on the kinetics and the mechanism of reactions in the solutions of molybdenum (VI) and potassium chlorate. In " Kinetics and the mechanism of heterogeneous and homogeneous chemical processes ". Chisinau: Stiinta (Russ.), 1977. - P. $24-31$.

[3]. Bardin, S.M.; Chikryzova, E.G. Studying of activating influence of mandelic acid and its polarographic determination in acid sulphate solutions of molybdenum and potassium chlorate / J. Anal. Chem.- 1978 - V. 33, No 2 - p. $358-363$.

[4]. Chiriac, L.; Revenco, M.; Cazac, T.; Cecoi N. The influence of some hydroxyl containing ligands on the polarographic catalytic current in the system Mo(VI) - potassium chlorate / The Int. Conf. dedicated to the 50th Anniversary from the Inst. Chem. Acad. Sci. Moldova. Book of abstracts. Chisinau, 2009 - P.219.

[5]. Kunihiko Yokoil; van den Berg, C.M.G. Simultaneous determination of titanium and molybdenum in natural waters by katodic stripping voltammetry /Anal. Chim. Acta. - 1992 - V.257, No 2. - p. $293-299$.

[6]. Quentel, F.; Mirceski, V. Catalytic adsorptive stripping voltammetry of molybdenum: redox kinetic measurements / Electroanalysis - 2004 - V.16, No 20. - p.1690 - 1696.

[7]. Safari, A.; Sharns, E. Selective determination of ultra trace concentrations of molybdenum by catalytic adsorptive stripping voltammetry / Anal. Chim. Acta - 1999 - V.396, No. 2-3. - p. $215-220$.

[8]. Ensafi, Ali A.; Khaloo, Shokooh S. Determination of traces molybdenum by catalytic adsorptive stripping voltammetry / Talanta - 2005. - V. 65 - p. 781-788.

[9]. Li, Hong; Smart, Ronald B. Square wave catalytic stripping voltammetry of molybdenum complexed with dihydroxynaphtalene / J. Electroanal. Chem. - 1997 - V. 429, No 1-2. - p. $169-174$.

[10]. Bersuker, I.B.; Bardina, S.M. The relation between the electronic structure of molybdenum oxalate complexes and their catalytic activity / Teor. and Experim.. Chem. (Russ.) - 1977 - V. 13, No 14. - p. 455 - 463.

[11]. Koldin, E. Quick reactions in the solutions (Russ.) M.: Mir - 1966- 285 p. 